\title{
El PAÍS DEL MAULE: COROGRAFÍAS LITERARIAS Y RESIDUOS GEOHISTÓRICOS*
}

\author{
Mario Verdugo **
}

\section{Resumen}

El artículo postula la existencia de un corpus ficcional unificado por su función geopoética, la de trazar discursivamente los contornos y singularidades del territorio que en esta serie de textos suele denominarse como "Maule Antiguo" o "país del Maule". Evocado a la manera de un ubi sunt o reconstruido a partir de sus residuos materiales y simbólicos, dicho territorio plantea tensiones respecto del mapa chileno hegemónico, ya sea resintiendo el rol tributario que le es impuesto, ya sea anclándose en una representación de tipo corográfico, ensimismada pero no desprovista de vínculos más allá de la nación. A través de las obras de Pablo de Rokha, Jorge González Bastías, Mariano Latorre, Efraín Barquero, Óscar Bustamante, Marcelo Mellado y otros autores, el Maule va emergiendo como un croquis de orientación transversal, a menudo en pugna con la longitudinalidad republicana.

Palabras clave: Maule, corografía, residuos, regionalismo, De Rokha.

\section{The Maule COUntry: LiTERARY CHOROGRAPHIES AND GEOHISTORICAL RESIDUES}

\begin{abstract}
The article postulates the existence of a fictional body, unified by its geopoetical function: to discursively trace the contours and singularities of the territory that in this series of texts is often called "Old Maule" or "The Maule country ". Evoked as a ubi sunt or reconstructed from its material and symbolic residues, that territory creates tensions regarding the hegemonic Chilean map, either affected by the tributary role that is imposed on it, or by being anchored as a chorographic representation, self-centered, but not devoid of links beyond the nation itself. Through the works of Pablo de Rokha, Jorge González Bastías, Mariano Latorre, Efraín Barquero, Óscar Bustamante, Marcelo Mellado and other authors, the Maule country emerges as a sketch of transverse orientation, often clashing with the republican longitudinality.
\end{abstract}

Keywords: Maule, chorography, residues, regionalism, De Rokha.

* Este trabajo se origina en el marco de los Talleres de Investigación en Literatura y Territorio, realizados en la Escuela de Arquitectura de la Universidad de Talca a contar de 2013.

** Chileno. Doctor en Literatura de la Pontificia Universidad Católica de Valparaíso. Académico de la Universidad de Talca, Talca, Chile. verdugoarellano@gmail.com 


\section{Introducción}

Como lo ha expuesto el geógrafo Andrés Núñez, el modelo monopólico de racionalidad territorial no alcanzó a suprimir acá las "perspectivas fragmentarias", "las historicidades específicas de regiones periféricas o de menor protagonismo" (173). A propósito de la dinámica de organización del Estado-nación en los siglos XVIII y XIX, Núñez establece que el Chile verticalizado -aquel que se ordena siempre de norte a sur y en el que las partes se integran al todo en virtud de infraestructuras como el ferrocarril o la carretera- acaba imponiéndose no sin conflictos a un modelo de ocupación que es más bien múltiple y disperso. La fijación de lo nacional en el espacio físico implica también un esfuerzo de posicionamiento en el imaginario, cuya consecuencia ha de ser la adhesión de los sujetos no centrales a la totalidad diseñada desde el centro, junto con algún grado de desarraigo respecto del entorno inmediato. Amén de lento, este proceso geohistórico de normalización no se desenvuelve sobre una tabla rasa, sino en continuo roce con experiencias y escalas previas, entre las que destaca la figura de un territorio cortado por los ríos, siguiendo el eje este-oeste al que el autor designa como "país de las cuencas". La imagen de diversos mundos prenacionales, reconvertidos paulatinamente en aras de Chile, sobrevive por lo menos hasta las postrimerías del XIX, e incluso es posible-según lo advierte Núñez- que siga presionando en el presente.

El río Maule y su cultura ribereña se cuentan entre los íconos perdurables de esa otra racionalidad, silenciada o segada con fines nacionalizantes (Núñez 174, 189). Acerca del espesor de su historia abundan las referencias, teniendo éstas como foco de interés a los ciclos de explotación económica (navegación fluviomarina, auge agrícola, balnearización), o a las sucesivas demarcaciones fronterizas (límite incaico, hispánico y patriota), o derechamente a las identidades hegemónicas y subalternas que allí conviven o batallan. En un libro cuyo título pareciese magnificar el valor de la región (Entre el Maule y el Amazonas), Arnold Toynbee señala su sorpresa ante las "modestas dimensiones"(9) del río que por entonces él sobrevuela, apenas un arroyo difícil de compaginar con una conmovedora prosapia cultural de varias centurias. Quizá decepcionante en términos de autoexaltación regionalista, el contraste observado por Toynbee apunta sin embargo a la 
hiperactividad simbólica que será resaltada en no pocas lecturas sobre la zona. Para Valeria Maino, por ejemplo, el Maule es el "río clave" (11) si se quiere conocer la evolución de las culturas fluviales en Chile, así como el río chileno con mayor número de estudios hidrográfico-portuarios y el punto de arranque de una experiencia que las comunidades en cuestión aún asumen como contemporánea, como una "idea que se resiste a morir porque forma parte del modo de ser de sus habitantes" (12). La visión este-oeste, conforme a las investigaciones de Maino, tiene al Maule como una especie de epítome e involucra una concepción del territorio distinta a la que fijan los sistemas modernos de comunicación y transporte.

Los abordajes a la historia maulina pueden mostrar un alcance circunscrito, como ocurre con el trabajo de Cortez y Mardones en torno a las densas memorias del puerto de Constitución, aunque también pueden enfrascarse con problemáticas más vastas, como las fuerzas identitarias centrífugas y centrípetas que se juegan en el llamado "río de las nieblas". Según veremos enseguida, el Maule acostumbra subsumirse dentro del imaginario hacendal expandido hacia el resto de la nación, desestimando con ello la heterogeneidad que otros documentos le conceden a sus diferentes tramos, cada uno poseedor de fisonomías y elementos paisajísticos particulares. Ya en el ámbito fictivo, la cuenca o el "país" del Maule -para usar el membrete que se repite más de una vez- cobra rasgos sui generis, recurrentes y resistentes a su disolución en los marcos omniabarcadores de una chilenidad uniforme. En un corpus que incluye novelas, cuentos, poemas y ensayos, este territorio se construye y reconstruye en la forma de una corografía, vale decir, como la descripción compleja y pormenorizada de un área específica, con relativa independencia de los espacios mayores que pudieran contenerla, y aun cuando un movimiento reflexivo secundario (por lo general un paratexto) la reubique en calidad de sinécdoque, parte, rincón o patria chica. Las corografías literarias del Maule se manifiestan mediante dos modalidades, de acuerdo a las articulaciones temporales de la enunciación y lo enunciado: una modalidad retrospectiva, elegíaca, que lamenta la pérdida sin vuelta de aquel microcosmos destruido en beneficio de agentes externos; y una modalidad residual, que pondera la significación de ese pasado -locus amoenus, belle époque, mera entelequiaen los signos admirables u ominosos de la actualidad. 


\section{Mapas y croquis}

Al margen de si es factible o no verificar empíricamente sus versiones del devenir histórico, lo cierto es que las mencionadas formas de representación conectan con la clase de organización prenacional que distingue Núñez. Corografía no constituye, desde luego, una noción por completo ajena al tráfico de términos geográficos hacia los estudios literarios y culturales. Gustavo Verdesio la emplea de hecho en sus indagaciones sobre el Uruguay colonial, comparándola con la actitud de quien pinta una nariz o una oreja sin remisión explícita a la cabeza o al rostro, y enlazándola luego con el fuerte localismo de algunos espaciamientos indígenas ${ }^{1}$. La reaparición de estos diseños, invisibles para la mentalidad totalizadora del colonizador, podría indicar por lo tanto la persistencia de unos modelos territoriales de data más antigua todavía. No por nada Renato Ortiz recuerda que la formación misma de la nacionalidad conlleva el reemplazo de un concepto acotado del espacio por otro donde rige la interconexión entre las partes antaño aisladas. La filología de la "nación" en Europa, siguiendo los argumentos de Ortiz (53), alude en principio a mundos recoletos, únicamente a la tierra donde se nace, de manera que el todo nacional-moderno sólo viene a solidificarse con posterioridad a su materialización en una vasta red de caminos y otros factores cohesivos.

Visto como "Región del Maule", o sea, como una división políticoadministrativa vigente pero de origen más o menos arbitrario, el territorio maulino queda inmerso en un macroespacio que la literatura y ciertas formulaciones académicas identifican con el Valle o Llano Central. De resultas, la transversalidad u horizontalidad características del dibujo corográfico, cuya dirección básica es el mismo curso fundante del río, cobra una apariencia cruciforme y a la vez ve reducirse sus pautas autónomas a una función tributaria, afluente del eje vertical/longitudinal que domina la jerarquía. "Lo dicho para el Maule [escribe Javier Pinedo ("Identidad" 159)] puede ser fácilmente aplicado a un amplio escenario que cubre

1 Espaciamiento es el término alternativo con el que Culler explica la différance derridiana (Culler 89), y sirve también para designar tanto una ordenación preexistente como un acto de ordenar, tanto una diferencia pasiva como una simultánea diferenciación, un nuevo modelo de espacialización o un nuevo mapa. El propio Derrida utiliza el vocablo francés correspondiente: espacement. Culler lo emplea en inglés como spacing y en la versión española aparece precisamente como "espaciamiento". 
desde Los Andes y San Felipe por el norte, hasta Concepción por el sur". Clasificando los modos de habitar que compartirían los residentes de la zona, Pinedo sopesa la importancia del aislamiento endogámico (reproducción consanguínea de las elites, economía no portuaria, escasa inmigración), además de la homogeneidad de las rutinas regionales (una sola cultura, indiferenciable de mar a cordillera) y el expansionismo casi imperialista de sus hábitos hasta los confines del Estado nacional: huasos y medialunas en Isla de Pascua, campesinos imponiendo su acento en el norte calichero, calles iquiqueñas nombradas en homenaje a próceres oriundos de Linares o Curicó.

La consagración del Valle como axis mundi de la identidad chilena, como macroespacio donde el Maule participaría sin ningún tipo de patrimonio privativo, coincide con el gran prestigio que escritores como Gabriela Mistral y Benjamín Subercaseaux le adjudican a ese núcleo identitario. Aquel "país de la muralla nevada", flanqueado por ambas cadenas montañosas, se torna a tal punto dominante que Subercaseaux refrenda la posibilidad de que se lo confunda con Chile en su conjunto (225). "Física y gubernativamente [afirma Gabriela $(128,189)]$, Chile es el Llano Central”, "tórax", "aposentamiento", "cuerpo histórico”, " autor orográfico y moral", "voluntad unificadora de nuestra geología". Asertos por el estilo habrían de reiterarse en discursos provenientes del saber antropológico e historiográfico. A juicio de Jocelyn-Holt, la sociedad agrario-señorial afincada en el Valle y autorreproducida por tres siglos podría hacernos prescindir del resto del país, "en un sentido groseramente simplista pero no enteramente falseable" (38-39). No pareciéndole necesario descontar los conflictos y rupturas sociales que allí se dan cita, ni la diversidad de relatos que allí coexisten (una memoria patriótica, una memoria católica, una criollista-popular), José Bengoa encuentra en el heartland del Valle a la cuna y a la retícula básica de la nacionalidad, el ecúmene en cuyos hombros -represiones mediante- se apuntala el Estado centralizado y autoritario que pronto irá a sentar sus reales en la Guerra del Pacífico y en la "pacificación" de la Araucanía².

2 La inscripción identitaria y geográfica del Maule en el Valle tendría una nueva expresión en el proyecto Ciudad Valle Central, promovido por la Escuela de Arquitectura de la Universidad de Talca (VV.AA, 2003). Este proyecto aspiraba a generar una nueva estructura urbana, de escala territorial, abarcando diez ciudades y valiéndose de la renovación de la carretera 5Sur y del entonces flamante nuevo ferrocarril Santiago-Chillán. 
Porque se cruza físicamente con el Valle, o porque una mirada foránea insiste en rebajar su carta de naturaleza a mero narcisismo de las pequeñas diferencias, el Maule se aprecia como un equivalente o una porción del mapa hegemónico que ha sido responsable de su declive o de su borramiento. En efecto, los dos trazados llegan a superponerse, y en alguna ocasión comparten símbolos, pero la verdad es que hay una serie ficcional donde se multiplican los datos de un punto de vista geopolítico alternativo. Las prácticas espaciales de contrahegemonía se despliegan con frecuencia "al interior" de la disposición ya normalizada y nacionalizada del territorio, en la misma latitud y en los mismos textos, por lo que es fácil omitirlas. Al respecto resulta muy ilustrativa la obra de Mariano Latorre, a quien se tiene por una suerte de coleccionista de tesoros provincianos, rincones heterónomos que se limitan a generar insumos para el erario estético y económico de Chile. En su "Elogio del Maule", publicado como prólogo a las Baladas criollas del poeta cauquenino Carlos Acuña, Latorre se refiere a un "Chile en miniatura", un país que repite a escala modesta "la configuración de Chile entero" ("Elogio" 11). Esta cartografía restringida a la representatividad sinecdóquica del espacio (a saber: la relación de caja china o muñeca rusa entre la parte y el todo), difiere no obstante de la propia multiplicidad no necesariamente chilenizable con que el "Elogio" va describiendo a la provincia maulina, y dista muchísimo del carácter conflictivo que tomará el vínculo en otros momentos:

[Fue] la ley fatal del progreso. El desarrollo agrícola de Chile planeó canales y tranques para regar los campos y el Maule se desangró en el valle central. Hacia su desembocadura, la corriente arrastraba torrentes de arena. La barra no era ya el choque de dos fuerzas contrapuestas, sino un muro de fango pesado e insidioso que se oponía a la marea. La navegación se hizo casi imposible. Ni las viejas lanchas pintadas de negro de los astilleros coloniales, o los faluchos forrados de cobre de época posterior podían salir de ahí, entregadas sus proas de roble en la húmeda gravidez de las arenas de la boca. (Chilenos 203)

Como el narrador precedente, que no puede estar más lejos de una visión conciliadora del impacto de lo nacional en lo regional, la voz que refiere los hechos en "Hijo del Maule" -acaso la ópera prima de 
Latorre- atribuye la depauperación de su "país" al desarrollo de ese otro país más grande que extiende su influencia longitudinal por el Valle. El microcosmos pierde el idílico apogeo de sus tiempos navegables, desvía su prosperidad, desparrama sus energías en pro de una agricultura que lo convierte en "corriente débil", en "vida pasiva" (32-33). Se diría que el Maule de Latorre no es cabalmente una provincia (un espacio inmóvil, reacio al cambio, sedentario en los lindes del vicio y la corrupción), sino hasta el instante en que sus recursos son enajenados, difuminándose así la atmósfera de cosmopolitismo e iniciativa mundonovista que le eran inherentes.

No se trata por cierto de una única conciencia autoral o narratorial, ni tampoco de una hipótesis única sobre el apocalipsis maulino. Lo que Latorre achacaba en 1912 y 1929 al embancamiento del río, debido no a una intervención divina sino a la acción geohistóricamente pesquisable de Chile y su punta de lanza (el Valle Central), va a repetirse ocho o nueve décadas más tarde en la narrativa de Óscar Bustamante, y a presentarse con versiones ligeramente disímiles en otros libros. "Guanayes [se lee en El día que se inauguró la luz, de Bustamante] ya no quedan, él es el último. Los demás desaparecieron cuando el río adelgazó, perdió profundidad, dejando de ser navegable. Fueron los canales de regadío los que lo mermaron para siempre" (62). El discurso aquí datado a finales del siglo XX se retrotrae al tiempo en que los barqueros del Maule llamados "guanayes"- padecen el colapso de su actividad productiva, y a partir de ese flashback narra la epopeya de un viejo guanay que vuelve a embarcarse, ya en el hic et nunc del relato, buscando rescatar a los sobrevivientes de una crecida. En una novela de Tomás Montecino, el fin de la navegación fluviomarina se correlaciona más bien con la llegada del ramal ferroviario entre Talca y Constitución, aunque para el caso los personajes experimentan el fenómeno de declive con la misma sensación invasiva: "la vejez prematura que la invasión de los hombres de progreso precipitaron sobre el río" (Los guanayes 100). Y si bien Cortez y Mardones endosan el cierre del ciclo marítimo al tren central -no a su ramificación costera, vivida en realidad por las comunidades involucradas como una esperanza de reimpulso-, el punto es que ante la gradual o abrupta reconversión del Maule en balneario se contesta con renuencia y sospecha. A los turistas de Talca y Santiago traídos por el ferrocarril, se los tendrá por sujetos afuerinos, expoliadores, desfavorecidos al cotejarlos 
con las costumbres de los antiguos inmigrantes europeos que a la sazón comenzaban a alejarse (Cortez y Mardones 192, 199).

Huelga mencionar que los textos ficcionales escrutados son textos topocéntricos, textos donde la tematización del espacio trasciende la evidencia marginal para exponerse como el quid de los acontecimientos y de la caracterización de los actores. En tales textos, el par binario vertical / horizontal se corporiza además como un lazo tenso entre lo que Armando Silva distingue como "mapa" (la representación del territorio de la nación, el statu quo que domina, ocupa y homogeiniza) y lo que distingue como "croquis" (el espacio "diferencial" que emerge o reemerge mentalmente desde las partes ocupadas). El croquis funciona de modo impreciso, se registra al nivel de la evocación y se traza con líneas difusas, pero no por ello menos complejas ni capaces de comprometer la subjetividad (Silva 50-52). A esas líneas difusas poco les concierne la materia verificable de lo evocado, puesto que toda su existencia se debate en la forma de vivenciar e imaginar individual y colectivamente el espacio. Aparte de las especulaciones sobre una presunta edad de oro, el corpus prodiga pistas descriptivas de naturaleza más puntual, donde es notoria la resistencia a las sugestiones unívocas del mapa: carretas y rodeos que en la costa y en los cerros del secano son de suyo diferentes a los del Valle (Latorre, Hombres 227; Mesa Seco, ¿Quién soy? 9); pescadores de Constitución que derivan hacia el agro o que imitan con ironía el acento de los huasos, marcando en ambas instancias la presencia de dos identidades contiguas pero no homologables (Montecino, Los guanayes 161, 221); bandoleros populares que combaten a quienes "vienen a imponer otra ley y otra cultura" (Mesa Seco, "Presentación" 19); nativos que repelen al talquino petimetre, fantoche, veraneante venido de apenas unos kilómetros más allá (Guerrero, Faluchos 45; Latorre, "Hijo" 17)3.

\section{Intertextos y fronteras}

Corografiado en decenas de discursos literarios, el Maule despunta como un universo completo y heterogéneo en su conformación interna.

3 En El tapete verde, original de 1910, Francisco Hederra Concha relata la luna de miel de un ludópata de Santiago (Max Blanco) y una aristócrata de Talca (Berta). Tras navegar por la confluencia del Claro y el Maule, Max y Berta se admiran de los "carretones plebeyos" y disfrutan de un picnic de langosta y champaña en las arenas de Constitución (95-113). Otra novela sobre la sociabilidad maulina y su comercio sentimental con forasteros es Playa negra (1947), de Luis Orrego Luco. 
Para la perspectiva regional, aquel territorio no es un primer escalón de la patria, una patria chica transitiva o resumida de la gran patria chilena. El despliegue de pormenores en sentido transversal se encarna en la figuración de toponimias profusas, nomenclaturas endémicas, hitos memorísticos que se reiteran y que terminan operando como una intertextualidad espacializada. La región se dilata hasta segmentarse, y los segmentos resultantes son los que dan pábulo al recorrido y el contraste. En relatos como Cuna de cóndores y Los guanayes, el Maule es objeto de una medición estimativa y directa, un cálculo menos relacionado con la abstracción y la técnica cartográfica que con las impresiones del ojo que contempla y el cuerpo que se desplaza. De la sierra al resguardo cordillerano puede haber dos días de marcha; cinco de cabalgata entre los ranchos y el fundo; veinticuatro horas de travesía en bote si se parte de Constitución rumbo a Perales; sesenta minutos en camioneta -por una autopista aún inexistente- desde la playa a la frontera con Argentina. Las líneas del croquis se tachonan con topónimos de embarcaderos, rocas y cerros que se suponen consabidos para todos los habitantes del "país", mientras que las referencias a personajes o lugares específicos saltan de un poema a otro, de una novela a otra: las niñas Carreño, por ejemplo, o el conductor Andrade, cuyos cameos se repiten en El amigo piedra (De Rokha 2), "Puerto mayor" (Latorre, Chilenos 173) y Faluchos (Guerrero 41, 135) $)^{4}$. Estos intertextos ratifican un conocimiento común, y activan la especie de reserva semántica que Michel de Certeau considera constitutiva del espacio practicado: una segunda geografía, poética, oculta y a la vez familiar, alternativa respecto de las planificaciones hegemónicas, y en la que los nombres propios cumplen la función de reactualizar lo que permanecía "en estado de jeroglífico", como "tiempos amontonados" o como "relatos a la espera" (121).

En tanto que el Valle Central, como lo ha hecho notar Juan Román en una tesis reciente, es un territorio sin gentilicios -salvo que allí se emplace la sede de "lo chileno"-, el Maule puede proliferar en pertenencias talquinas, costinas, serranas, curillincanas, mauchas, inclusive "constitucionenses", según la inusual denominación presente

4 Este intertexto de cuño regional rara vez escamotea referencias al cerro Mutrún, la estatua de Mercurio en Constitución, los astilleros, el puente Banco de Arena, la Poza, la barra en la desembocadura, el ramal, la explotación aurífera en Putú, los faluchos y sus barqueros, el pequeño puerto de Perales, el embancamiento del Maule y las confluencias de éste con los ríos Claro y Loncomilla. 
en Leoncio Guerrero (Faluchos 143). La variopinta contextura visible en el recorrido este-oeste permite que los desplazamientos interiores posean un significado crucial, como en "El bonete maulino" de Manuel Rojas $^{5}$; un significado que no alcanza a ser anulado si se atiende a las precarias condiciones infraestructurales de la respectiva época. El primer capítulo de Faluchos retoriza este recorrido con la metáfora de las edades, de manera que un río-niño surge irresponsable desde las montañas, madura en los huertos, contrae nupcias con las aguas del Loncomilla, se retuerce en los rápidos y concluye ahogándose en el Pacífico. A riesgo de desvirtuarlo en el chiste, la novela de Guerrero exacerba el prurito corográfico de los del Maule por medio del "marinero Pérez", un nativo que se hastía de oír la lista de países conocidos por un turista lechuguino (España, Francia, Italia, Alemania...), y que a eso responde enumerando su personal y más abultado prontuario de viajes: Colín, Rauquén, Huenchullamí, Putú, Cobquecura, Quivolgo, Junquillar, Curepto... (131).

Que la economía y la arquitectura naval y habitacional tengan en el croquis una índole autárquica, eficiente a base de los suministros dispensados dentro del "país", no debiese inducir a pensar que se está frente a un espacio exento de comunicaciones internacionales. Los faluchos no se tallan sino en el tronco del roble maulino o pellín (Latorre, Chilenos 174); las fiestas se animan con el vino de la comarca (Montecino, Los guanayes 295); y las casas de los pueblos se edifican con barro, con las "excrecencias de la tierra árida" (Latorre, Hombres 96). El Maule, sin embargo, no cesa de vincularse con el extranjero tanto por su límite oriental, a través de las sendas transcordilleranas de los arrieros y bandidos, como por el poniente, a través de los faluchos que transportan mercancías hacia el Callao y Guayaquil; Panamá, California, Tahiti y acaso Australia, de acuerdo a la versión de Mesa Seco ("Presentación" $20)^{6}$. En el caso de los Andes, el engarce internacional hunde sus raíces en un período anterior a las actividades ganaderas y al proceso de normalización del XIX. Según se detalla en un artículo de Hugo Capellà,

5 En el cuento de Rojas, la dialéctica entre sedentarismo y dinamismo adquiere cuerpo en la oposición entre Talca y el interior agreste de la provincia, ocupado por bandoleros. Santiago, por su parte, aparece como lugar de acopio de especificidades culturales y al mismo tiempo como un extrarradio que propicia el ocultamiento.

6 Acerca de los inputs y outputs del circuito ribereño, una fuente de otra disciplina es el film documental El Maule (1983), de los hermanos Juan Carlos y Patricio Bustamante. La película parte en el dominio de los arrieros y finaliza con la salida de las embarcaciones hacia el Pacífico. 
la franja del Maule forma parte de las etnorrutas que la cultura mapuche conoce como nampülkafe, es decir, búsqueda espiritual y comercial extendida hacia las pampas trasandinas, el puelmapu u oriente sagrado. La integración indígena con el este tendería también a borronearse en la linealidad del sesgo norte-sur, a guisa de precuela de lo que ocurrirá con el país de los guanayes ${ }^{7}$. La impronta borbónica, por lo demás, tiene el efecto de una "derrota identitaria" (Morales 11), lo cual se expresa en el ordenamiento forzado que convierte una ocupación inestable, juzgada como caótica, en controlables ciudades coloniales y pueblos de indios. Con siglo y medio de antelación al declive maulino, las políticas de poblamiento de la corona española redundan en un primer "momento modernizador" (Pinedo, "La fundación" 22), también en pugna con las perspectivas transversales, también impuesto por el eje civilizatorio del Valle.

Nada cuesta entender que el espacio sólo se hace provinciano cuando está sujeto, cuando es dependiente, tributario en este caso de España o de Chile. La sujeción a la metrópoli nacional es harto menos palmaria en un espaciamiento corográfico como el que se bosqueja a propósito del Maule. Puede advertirse en ocasiones un vaivén entre mapa y croquis, o una momentánea interposición de lo dominante en las líneas difusas del territorio diferencial: la definición del río como dramatis personae de la historia de Chile en Carlos Acuña (Nacimiento); aquel ejemplar de Raza chilena que los puesteros de Cuna de cóndores incluyen en sus pertrechos; la obstinación -en "El bonete maulino"- con que el protagonista pretende llevarse suvenires o trofeos regionales de regreso a Santiago. Lo que prima, no obstante estas excepciones, es la descripción de circuitos endógenos que casi nunca se ligan con la capital de la República, excepto cuando revelan el espurio bildung que allí se promete y el ofensivo desprecio que sus autoridades exhiben por las coordenadas de la región (Montecino, Los guanayes 169, 253). Se sale por mar hacia Valparaíso, hacia Antofagasta o hacia Perú (Guerrero, Faluchos 157-169); se dialoga con los "cheyes" argentinos o se pelea con ellos en un duelo de corvo contra facón (Latorre, Cuna 146); se acepta y justiprecia a los franceses, ingleses, vascos y alemanes que alientan el auge del comercio

7 La historia de los geosímbolos mapuche y su cosmovisión este-oeste pueden consultarse en las investigaciones de Álvaro Bello (2011). 
y los astilleros (Latorre, Chilenos 153, 174); se piensa y se transita en otras latitudes, pero rara vez se piensa y se transita -voluntariamente por lo menos- en Chile.

\section{Elegías y permanencias}

Las corografías maulinas -ya está dicho- se patentizan en formato de lamento elegíaco o de afirmación contemporánea de su continuidad o sus alteraciones. Una y otra variante, bien por el contenido enunciado, bien por el acto mismo de su enunciación, hablan de una gravitación duradera, sea cual sea su sello axiológico. Las numerosas elegías hacen comparecer un mundo en descomposición o ya descompuesto: el campo arrugado y yermo de Pichamán (Guerrero), el caserío agonizante en El lugar sin limites (Donoso), la fauna extinta y la demografía implosiva en Hombres y zorros (Latorre), las aldeas y los aldeanos espectrales que pululan por las primeras páginas de El amigo piedra (De Rokha), la miseria que se cierne sobre los huertos en El poema de las tierras pobres (González Bastías). Estas constataciones o evaluaciones desdichadas se imbrican por lo general con la celebración de lo que fue, engrandeciendo así la memoria de un espacio ubicado in illo tempore o más frecuentemente en el esplendor decimonónico y cosmopolita, trasunto de una cultura que entonces no es sólo de cabotaje ni todavía de provincia tributaria.

Conforme al movimiento oscilatorio que a menudo se registra entre mapa y croquis, el descalabro del Maule puede insertarse en una catástrofe de orden nacional, cuyo victimario no sería Chile en abstracto sino una fracción de su sociedad radicada en la metrópoli y cooptada por nefastos poderes extranjeros. Ejemplos de lo anterior son las imprecaciones que De Rokha descarga, en Idioma del mundo, contra la industria maderera y su depredadora y erosiva intervención en los bosques de pellín (89). Por otro lado, la injerencia longitudinal-centralista puede actuar como un trasfondo tácito, mediante el deterioro detectable en los pueblos que quedan al margen de la experiencia moderna: el caso, sin ir más lejos, de la Estación El Olivo de José Donoso (El lugar), puesta a trasmano de la infraestructura vial y desprovista de red eléctrica ${ }^{8}$. En el corpus

8 La intensa explotación hidroeléctrica en las últimas décadas del siglo veinte puede ser vista como un nuevo capítulo de la verticalización del Maule. En cuanto a Donoso, su anclaje en la región no se agota evidentemente con esta novela. Botón de muestra: el papel fundante de la "conseja maulina" en El obsceno pájaro de la noche. 
las conflictividades más implícitas corren a parejas con la denuncia meridiana, como ese espeso "muro de fango" que Latorre ve instalarse tanto en la boca del río como en su identidad otrora fluida y ahora a merced de los requerimientos del Valle. Los cuentos del autor nacido en Cobquecura aparecen como prototipos de la simultánea exaltación de aquella "tierra privilegiada" -el "Maule Antiguo", "nuestro pequeño paraíso maulino", (Chilenos 212)-, y el clamor por la debacle que significa su transformación en "esclava servil de Talca o de las gentes de Santiago" (Chilenos 203):

No es la ría del Maule lo que fue entonces. El puerto comercial dominó al balneario. Ahora, el balneario ha absorbido al puerto. La barra, a pesar de sus cambios inesperados, nunca fue un obstáculo para la salida de vapores y veleros, lanchas y faluchos, conocidos en toda la costa del Pacífico hasta San Francisco de California ... Se teñía de cosmopolitismo el villorrio que fundó Oñederra ... Aislado y rico, el Maule se bastaba a sí mismo. (Chilenos 173-174)

Hasta el mismo río era más lindo. Aguas azules que iban quietamente al mar, después de abrazar la isla con una cintura espumosa ... Hoy el río parece alejarse de la tierra. Corre desanimado, sucio, lleno de bancos de arena, y hasta los pejerreyes han huido mar afuera ... ¡Tiempo delicioso ido para siempre, con los talles estrechos y las levitas ajustadas, los vapores de rueda y los buques de vela, las muchachas tímidas y los novios románticos! (Chilenos 207-216)

El Maule Antiguo evocado por Latorre nutre "la imagen de ciudad próspera que mantienen los intelectuales [regionales]" (Cortez y Mardones 9). En los Cuentos del Maule, la oposición se iconiza a través de la barra costera y el ferrocarril, instrumentos del "valle agrícola" que "mata" a los guanayes y a los marinos (Latorre, "Hijo" 18-20). Este elenco de víctimas elegíacas se abre también hacia la sierra, donde un quijotesco cazador de pumas, "On Panta" alucina con "absurdos episodios" de un siglo atrás, atrayendo en consecuencia la burla y la caricatura (Latorre, On Panta 29). El contraste de abundancia y escasez -en palabras de Javier Pinedo ("Identidad")- se asienta aquí como uno de los principales nudos del imaginario, lo que se vislumbra con total claridad en la obra poética de Jorge González Bastías. Comprometido con su entorno al extremo de 
que su nombre designa hoy al pueblo antes llamado Infiernillo, González dedica su segundo libro al río y a las sombras que vagan en derredor, "añorando por sus tierras / ahora infecundas" (9). Nada de lo que era en la bonanza ribereña, con excepción de la leyenda o el recuerdo, parece pervivir en un presente desecado por los "hombres infames", un presente transido de casas arruinadas, hijos andrajosos y "miseria nueva" (13-14).

Por descontado que la recurrencia del ubi sunt acarrea problemas de perspectiva, parcialidades sociales que se añaden a la diferenciación de los paisajes (mar, valle, cordillera) como elementos reveladores de una complejidad interna. Difícilmente podría hacerse equivaler al hablante de Armando Ulloa en Poemas de la tierra con el de Pablo de Rokha en "Tonada a la posada de don Lucho Contardo". El primero acentúa la separación entre un sujeto activo y uno contemplativo, entre la voz del propietario y el silente ajetreo del "dulce labriego", entre el intelectual que se echa a rimar bajo el parrón de la casona (copa de vino en mano, libro de Fray Luis a la vista) y el lugareño que el propio poema conmina a abrir los surcos con sangre, sudor y lágrimas, pues ya "mi heredad" repartirá sus frutos (30-39). De Rokha, en cambio, introduce una espacialidad en que las clases se entremezclan, "comiendo de la misma aceituna", pero donde sin dudas hay una toma de partido por los "súbditos patipelados", los arrieros de paso hacia Cuyo o Curillinque, los peones a los cuales esquilma -en aquel momento "finisecular del Novecientos"- un enemigo expresamente identificado con el capitalismo imperialista y el latifundio oligárquico (203-212).

La naturaleza elítica y endogámica que el país del Maule ofrece de vez en cuando en las añoranzas de Mesa Seco o Carlos Acuña ${ }^{9}$ se contrapone asimismo con el giro proletario posibilitado por Efraín Barquero en La piedra del pueblo. El texto de 1954 preserva el sentido fundador que la ex Nueva Bilbao depara para la subjetividad, aprovechando esta vez la bisemia del vocablo en uno de los subtítulos: "Constitución de mi canto", Constitución como topónimo, Constitución como el lugar donde se constituye el sujeto poético. Habiendo emigrado

9 Estas disquisiciones, en efecto, pueden contener sesgos étnicos: la raza blanca y rubia que perduraría en la Cordillera de la Costa (Mesa Seco, "Presentación" 18); o fraternos y filiales, como el modo en que Acuña subraya su parentesco de sangre con otro poeta regionalista ("Palabras" 8), o el propio Mesa su ilustre linaje y los viejos lazos de amistad entre su familia y la de González Bastías, por ejemplo ("Presentación" 6-7). 
a la metrópoli, según el esquema típico de la poesía lárica, este sujeto continúa autorreconociéndose en el microcosmos de la infancia: “QQuién soy, me preguntas, Mapocho / Soy un poeta que ha llegado hace poco / del Maule al barrio donde limpias la aurora. / De allá del Maule vengo. Soy un falucho / cargado de madera y de pescadores ahogados. / He dejado atrás Maquegua, Huinganes, Tanguao" (111) ${ }^{10}$. El microcosmos que Barquero bosqueja, sin embargo, es un microcosmos dividido, domicilio de dominadores y dominados, hogar tanto de industriales que se apoyan más en el privilegio capitalista que en el prestigio capitalino, como de obreros locales que van a entregar sus fuerzas a la sevicia y a la herrumbre de un "barco negro" (97).

El Maule es en Mesa Seco un "pequeño gran país" (¿Quién soy? 15), un "país" a escala en Latorre ("Elogio"), el "país" de los guanayes -al que desconocen los funcionarios metropolitanos de Obras Públicas- en la narrativa de Tomás Montecino (Los guanayes 50, 231, 253). Procurando ensalzarlo sin pudores, De Rokha retrata al río como un "señor patriarca" (El amigo 64); Acuña, como un "Danubio" que refresca el magín de multitudes de artistas ("Palabras" 8); Mesa, como un "ser mitológico" que riega el verbo de los poetas ("Presentación"14); y Montecino, como la corriente en cuyos roqueríos el "Genio del Mar" consuma sus bacanales con la "diosa Maule" (Los guanayes 50; El camino 6) ${ }^{11}$. La empresa colectiva de mitificación funge en cualquier caso como uno de los pretextos sobre los que se monta la figuración residual del croquis, una figuración más reciente y, cabría decir, de cota triple, puesto que los revivals maulinos acontecen en un nivel diegético (cuentos y novelas de tematización ad hoc), en un nivel paratextual (antologías y prólogos que sancionan el canon literario de la zona) y en un nivel paródico (de nuevo cuentos y novelas, aunque prestos a servir ahora como metalenguaje, como respuesta cómica a las desmesuradas teorías de la "maulinidad").

10 Sobre la raigambre vital y literaria maulina de Barquero -niñez en Constitución y Talca, tempranas y productivas lecturas de González Bastías y Latorre- la referencia básica es su texto autobiográfico Arte de vida, de 1971.

11 Las apologías del Maule mítico, ente no sólo físico sino también "moral" y "creador" según Mesa Seco (¿Quién soy? 12), tienden a escoltarse con antecedentes literarios prestigiosos, como el del abate Molina consternado ante un caudal que podría llenar las cuencas del infierno (Mesa Seco, ¿Quién soy? 11) o las menciones del Inca Garcilaso al río "Maulli" (Acuña, Nacimiento 14). A esta constante se suma la especulación sobre los genuinos límites del "país". Una de las demarcaciones habituales es la que prolonga las fronteras del Partido o Corregimiento colonial del Maule: los cerros de Teno por el norte y el Perquilauquén por el sur (Opazo Maturana 69). 
Ramal, de Cynthia Rimsky, se planta ejemplarmente en la cota uno. A casi cien años exactos de los inaugurales Cuentos de Latorre, Ramal comienza con la anécdota de un burócrata del servicio de turismo, interesado en salvar pueblos perdidos y en especial el trayecto ferroviario que va de Talca a Constitución. Al burócrata cuya onomástica se restringe a un rótulo vago o genérico ("el que viene de afuera"), le sorprende la ostensible distancia entre lo que lee y lo que ve: textos sobre el Maule, por un lado, y escenas maulinas por el otro. Las conductas reacias y aun maleducadas de los lugareños, junto con el estado ruinoso del ambiente (cuatro palos donde alguna vez estuvo un paradero, estaciones donde sólo se mantiene la fachada, falsas tejas que simulan antigüedad, trenes que no llegan o que llegan con retraso), terminan defraudando las expectativas del afuerino durante su visita a Colín, Pichamán y Maquegua. De lo que fue una boyante economía fluvial y luego un bello itinerario hacia la playa, apenas resta el mal olor de la industria celulosa y la queja bovarysta de unas muchachas que sueñan con quedarse viendo la televisión por cable en una pensión de Talca. Para el punto de vista nativo, pese a todo, la herencia del Maule es algo de lo que todavía se puede hablar en presente (56).

Como en Rimsky, los relatos de Óscar Bustamante marcan la persistencia del trazado corográfico o de las líneas difusas y vívidas del croquis, inclusive en su metamorfosis al concluir el siglo veinte. Son, con pleno derecho, "residuos", en el sentido que a esta noción le otorga Williams: elementos formados en el pasado pero que permanecen vigentes y activos dentro del proceso cultural, remanencias que aún se practican y que aún tienen un influjo significativo, normalmente en pugna con la cultura dominante y mucho más allá del puro arcaísmo de museo (144). En El día que se inauguró la luz, la instalación del tendido eléctrico en una aldea del Maule entraña por supuesto una clave modernizadora, tal como en El lugar sin límites de José Donoso, si bien los personajes de Bustamante no reaccionan con genuflexiones sino con sorna, incrédulos ante esa faramalla centralista que jura sacarlos de una vida de tinieblas y por ende inculta, "a tientas" (El día que se inauguró 73-78). El río reasoma porfiadamente en las conciencias como sobresalto nostálgico o como espectáculo en vivo; y a las formas susodichas del ubi sunt ("aquel tiempo cuando el Maule dejó de ser lo que era", 64), se yuxtaponen las híbridas facetas actuales: el espacio de siempre, pero abierto al consumo o al uso de refrigeradores, cerveza, blue jeans, kiwis y casacas de cuero. 
En el nivel paratextual los residuos se concretan a través de la creación de parnasos literarios: diccionarios, antologías o catálogos que pretenden realzar la identidad del territorio con auxilio de los autores que allí han nacido o residido, así como de las obras magnas u ordinarias, portentos o mamarrachos que sobre el "país" se han escrito. La estrategia se legitima en virtud de la hipotética capacidad del río -como se entrevió hace unos párrafos con los ditirambos de Acuña y Mesa Seco- para regar el verbo y refrescar el magín artístico. Tan superabundante sería el Maule en lo que atañe a la generación de poetas, que Emma Jauch se pregunta si acaso no es con propiedad el "río literario de Chile" (13). De costumbre, las páginas en que se aloja cada parnaso vienen justificadas por una categoría esencializante: la "maulinidad"12, y al amparo de sus más o menos inclusivos criterios de selección se han ido apilando volúmenes abigarrados: Poetas de la región del Maule (1973), Diccionario de autores de la región del Maule (1984), Nueva antología poética del Maule (2001), y Poetas del Maule: antología poética para el bicentenario (2007). Desentendido del valor estético, el ingreso al parnaso generalmente se realiza con arreglo a la identificación territorial, esto es, al mérito de una filiación comprobable y a veces escarpada, como los dos o tres decenios de residencia que se exigen en el segundo caso. De ese modo el provecho a la larga resulta recíproco, pues algunos de los incluidos pueden medrar de una canonización compensatoria -oriundez o afincamiento que los hermana con un Premio Nacional o un Premio Nobel-, mientras que el territorio cuenta con un aval cuantitativo para sus cualidades de sugestión lírica: "lugar privilegiado", "vergel" que parece repercutir según conjetura Nómez (18)- en lo profundo de la siquis creadora.

En el nivel paródico, por último, los maulinistas adquieren también una expresión fictiva. La creación de parnasos y los parnasos mismos entran al espacio de la diégesis, y esta participación como base pretextual no hace sino corroborar una vez más la presencia de residuos, máxime teniendo en cuenta que el pretexto parodiado -de acuerdo a las formulaciones de Linda Hutcheon (citada en Amícola 107)- resiste la

12 En el prólogo a Rafide \& Villablanca (Nueva antología), se habla de compartir "los valores de la maulinidad" (7). Los prefacios a Rafide et al insisten en los "valores de la esencialidad de nuestra historia poética" (12), sin dejar de destacar al Maule como "esencia conductora" de la "cultura maulina" (12-13). 
superposición de la ironía y se afirma por su sola introducción en el texto parodiante. Informe Tapia, de Marcelo Mellado, narra las vicisitudes de un campeonato entre la "Asociación de Poetas de la Cuenca del Maipo" y su similar del Maule. A la cita cada grupo llega con sendas antologías: los maulinos con una obra "monumental y enciclopédica", los de San Antonio con unas míseras hojas de roneo. El maulinismo rivaliza en la magnitud y la excelencia de su patrimonio, se disputa la pertenencia de Efraín Barquero, y ya en el clímax lo acusan de connubios con la ideología nazi. Si en Informe Tapia las referencias paródicas son directas o à clef-sobre todo a Matías Rafide y Enrique Villablanca, firmantes de la ya señalada Nueva antología-, en un cuento de Andrés Gallardo la alusión es harto más ambigua: dos investigadores, don Ramiro Saavedra y don Ángel Soto-Ahrens, que se pelean la primacía de los estudios sobre literatura maulina, acusándose recíprocamente de traicionar la esencia regional. Contadas sus discrepancias, Saavedra y Soto-Ahrens conforman con sus trabajos "un solo texto complejo" (20), un enfoque clasificatorio apoyado en tradiciones específicas y para el cual la metrópoli supone una otredad negativa y usurpadora, como lo ratifica la exclusión de Mariano Latorre del canon maulino "por haber ido a terminar sus días en la cuenca corrupta del Mapocho pestilente" (17). El cuento de Gallardo imita la retórica de un paper, aunque pronto descompone la ortodoxia del género con la intromisión de cierta trama biográfica: toda la trifulca entre los investigadores del Maule se explica, al fin y al cabo, como la burda secuela de un lío de faldas, o como el mutuo resentimiento que esos "viejos poetas lachos decidieron canalizar por la vía de la polémica literaria" (25).

\section{Conclusiones}

A partir de la recurrente tematización del "país del Maule" es posible establecer un corpus de textos y paratextos ya secular, en el que los residuos materiales y simbólicos del espacio delineado se dan con intensidad topocéntrica. En definitiva, es la chance de escapar a un destino tributario, ensimismando la descripción, lo que se juega en estos trazados de zonas más pequeñas que el territorio nacional, latentes en la propia ambivalencia de la palabra "país" - a un tiempo "parte" y "todo", según el étimo recogido por Kessler (9)-, y ya entrevistos, al parecer, en unas líneas introductorias a La Araucana: "Chile es una provincia grande 
que contiene en sí otras muchas provincias" (Ercilla 4). Un repertorio de oposiciones también espacializadas surgen del vínculo conflictivo entre el statu quo de la nación y el reforzamiento de las diferencias regionales. Verticalidad y horizontalidad, valle y río, norte-sur y esteoeste, cartografía y corografía, carreteras y cuencas, dominancias del mapa y remanencias del croquis, acaso tengan un correlato adicional en el par binario que Gustavo Verdesio emplea para distinguir las representaciones territoriales modernas en "copia dura" (mapmaking), y el enfoque más bien particularizante y directo, nunca uniformizador, característico de algunas comunidades indígenas (mapping).

Las obras de Pablo de Rokha, Leoncio Guerrero, Jorge González Bastías, Manuel Francisco Mesa Seco, Óscar Bustamante y Andrés Gallardo entre otros, muestran la incidencia no menor de una experiencia centrípeta del mundo, un modo de autoorganización y construcción de la realidad que suele actuar bajo el criterio de sus códigos específicos, regionalmente fijados, antes y después de su verticalización nacionalista, sin que ello comporte desentenderse de latitudes externas, aquí corporizadas en las rutas transcordilleranas y fluviomarinas de arrieros y marineros. Con puntos de vista disímiles, a menudo cruzados por intereses de clase, la actividad discursiva desempeña esta vez una función geopoética, constructora y reconstructora de territorios y de jerarquías espaciales. Desde los Cuentos de Latorre, y hasta Ramal de Rimsky e Informe Tapia de Mellado, la literatura del Maule adopta el formato preferente de la elegía, para renovarse más tarde de en el tono apologético o burlesco del parnaso y la parodia. 


\section{Bibliografía}

Acuña, Carlos. Baladas criollas. Santiago: Nascimento, 1940.

. Nacimiento de Nueva Bilbao: apuntes sobre su fundación. Santiago: s.n., 1944

- "Palabras que comienzan el libro". Prólogo a Armando Ulloa.

Poemas de la tierra y otros poemas. Santiago: Nascimento, 1931. 5-8.

Amícola, José. Camp y posvanguardia. Manifestaciones culturales de un siglo fenecido. Buenos Aires: Paidós, 2000.

Barquero, Efraín. La piedra del pueblo. Santiago: Alfa, 1954. . Arte de vida. Santiago: Universitaria, 1971.

Bello, Álvaro. Nampülkafe. El viaje de los mapuches de la Araucanía a las pampas argentinas: Territorio, cultura y politica en los siglos XIX y XX. Temuco: UCT, 2011.

Bengoa, José. Valle Central. Memorias, patrimonio y terremoto en haciendas y pueblos de Chile Central. Santiago: Catalonia, 2012.

Bustamante, Óscar. El día que se inauguró la luz. Santiago: Sudamericana, 1998.

Capellà, Hugo. "Por los caminos de la identidad y del desarrollo regional". Atenea 500, (2009): 75-90.

Cortez, Abel y Marcelo Mardones. Constitución 1794-1915. Astillero, Puerto Mayor y Ciudad Balneario. Constitución: Pocuro, 2009.

Culler, Jonathan. Sobre la deconstrucción. Madrid: Cátedra, 1984.

De Certeau, Michel. La invención de lo cotidiano: 1 Artes de hacer. México DF: Universidad Iberoamericana, 2000.

De Rokha, Pablo. El amigo piedra. Santiago: Multitud, 2011. . Idioma del mundo. Santiago: Das Kapital, 2010. - "Tonada a la Posada de don Lucho Contardo". Escrito en Rokha. Antología poética de Pablo de Rokha. Talca: Universidad de Talca, 2015. 203-239. 
Donoso, José. El lugar sin límites. Barcelona: Bruguera, 1984. El obsceno pájaro de la noche. Barcelona: Seix Barral, 1992.

El Maule. Dir. Juan Carlos Bustamante y Patricio Bustamante. Valcine/ Bustamante Producciones, 1983. Película.

Ercilla, Alonso de. La Araucana. Salamanca: Domingo de Portonarijs, 1574. Memoriachilena.cl (2015): s.p. Web. 2 Feb. 2015.

Gallardo, Andrés. Historia de la literatura y otros cuentos. Concepción: Andalién, 1982.

González Bastías, Jorge. El poema de las tierras pobres. Valparaíso: Inubicalistas, 2013

Guerrero, Leoncio. Pichamán. Santiago: Yunque, 1940. . Faluchos. Santiago: Pineda Libros, 1973.

Hederra Concha, Francisco. El tapete verde. Talca: Universidad de Talca, 2004.

Jauch, Emma. ¿Quién soy? Santiago: Agrupación Amigos del Libro, 1978. Jocelyn-Holt, Alfredo. "El Valle Central (pasado, presente y futuro)". Revista de la Escuela de Arquitectura de la Universidad de Talca 2 (2008): 36-43.

Kessler, Mathieu. El paisaje y su sombra. Trad. Fernando González del Campo. Barcelona: Idea Books, 2000.

Latorre, Mariano. Cuentos del Maule. Santiago: Zig-Zag, 1912. . Cuna de cóndores. Santiago: Universitaria, 1917. . Chilenos del Mar. Santiago: LOM, 1998.

- "Elogio del Maule". Prólogo a Carlos Acuña. Baladas criollas. Santiago: Nascimento, 1940. 11-29.

.. Hombres y zorros. Santiago: Ercilla, 1937. . On Panta. Santiago: Ercilla, 1935. . "Puerto mayor". Chilenos del mar. Santiago: LOM, 1998. 173-206. . Viento de mallines. Santiago: Zig-Zag, 1944. 
Maino, Valeria. La navegación del Maule. Una vía de conexión con el exterior. 1794-1898. Talca: Universidad de Talca, 1998.

Mellado, Marcelo. Informe Tapia. Santiago: La calabaza del diablo, 2004.

Mesa Seco, Manuel Francisco. "Presentación del Maule". Algunos aspectos culturales del ancestro provinciano de Neruda. Santiago: Nascimento, 1985. 11-39.

____ ¿Quién soy? Santiago: Agrupación Amigos del Libro, 1977.

Mistral, Gabriela. Recados contando a Chile. Santiago: Editorial del Pacífico, 1957.

Montecino, Tomás. El camino de la poza. Santiago: Cruz de Triana, 1950. . Los guanayes. Santiago: Nascimento, 1946.

Morales, Alejandro et al. Thalcamo: tierra y pueblos de indios del Maule. Talca: Junta de Adelanto del Maule / Museo O'Higginiano, 2012.

Nómez, Naín. "Poetas del Maule: en los ríos profundos de la tradición moderna". Poetas del Maule. Antología poética para el bicentenario. Talca: Universidad de Talca, 2007. 1719.

Núñez, Andrés. "Definiendo una geografía para la nación: la resignificación territorial de Chile, siglos XVIIXIX". Quim Bonastra y Gerard Jori, eds. Imaginar, organizar y controlar el territorio. Nuevas perspectivas surgidas del XII Congreso Internacional de Geocrítica. Barcelona: Icaria, 2013. 167-196.

Opazo Maturana, Gustavo. Historia de Talca. Santiago: Imprenta Universitaria, 1942.

Orrego Luco, Luis. Playa negra. Escenas de la vida en Chile. Santiago: Nascimento, 1947.

Ortiz, Renato. Mundialización y cultura. Bogotá: Convenio Andrés Bello, 2004.

Pinedo, Javier. “Identidad de la Región del Maule. Reflexiones e imágenes sobre el tema". Universum 14 (1999): 151-180. 
. "La fundación de las ciudades del Valle Central de Chile y su contexto histórico, identitario y cultural". VV.AA. Ciudad Valle Central. Talca: Escuela de Arquitectura de la Universidad de Talca, 2003. 21-33.

Rafide, Matías. Poetas de la Región del Maule. Talca: UCM, 1973. . Diccionario de autores de la Región del Maule. Talca: Delta, 1983.

Rafide, Matías y Enrique Villablanca. Nueva antología poética del Maule. Curicó: Mataquito, 2001.

Rafide, Matías et al. Poetas del Maule. Antología Poética para el Bicentenario. Talca: Universidad de Talca, 2007.

Rimsky, Cynthia. Ramal. Santiago: FCE, 2011.

Rojas, Manuel. El bonete maulino y otros cuentos. Santiago: Universitaria, 1968.

Román, Juan. "Del Valle Central de Chile como soporte de un quehacer". Tesis para optar al grado de doctor en arquitectura y patrimonio. Universidad de Sevilla, 2015.

Silva, Armando. Imaginarios urbanos. Bogotá: Tercer Mundo editores, 1998.

Subercaseaux, Benjamín. Chile o una loca geografía. Santiago: Ercilla, 1946.

Toynbee, Arnold. Entre el Maule y el Amazonas. Trad. Mary Williams. Santiago: Francisco de Aguirre, 1997.

Ulloa, Armando. Poema de la tierra y otros poemas. Santiago: Nascimento, 1931.

VV.AA. CiudadValleCentral. Talca: Escuela de Arquitectura de la Universidad de Talca, 2003.[6][7]

Verdesio, Gustavo. "Las representaciones territoriales del Uruguay colonial: hacia una hermenéutica pluritópica". Revista de Crítica Literaria Latinoamericana 46 (1997):135-161.

Williams, Raymond. Marxismo y literatura. Trad. Pablo di Masso. Barcelona: Península, 1997. 